\title{
Meconium-stained amniotic fluid: a risk factor for postpartum hemorrhage
}

This article was published in the following Dove Press journal:

Therapeutics and Clinical Risk Management

\section{Carlo Bouchè \\ Uri Wiesenfeld' \\ Luca Ronfani' \\ Roberto Simeone ${ }^{2}$ \\ Paolo Bogatti \\ Kristina Skerk' \\ Giuseppe Ricci',2}

'Institute for Maternal and Child Health, IRCCS Burlo Garofolo, Trieste, Italy; ${ }^{2}$ Department of Medicine, Surgery and Health Sciences, University of Trieste, Trieste, Italy
Correspondence: Giuseppe Ricci Institute for Maternal and Child Health, IRCCS Burlo Garofolo, Via dell'Istria $65 /$, Trieste 34137 , Italy

Tel +3940378535I

Fax +394076I266

Email giuseppe.ricci@burlo.trieste.it
Background/aim: Clinical data with respect to the impact of meconium on the risk of maternal hemorrhage are scarce. Therefore, in this study, we aimed to determine whether meconiumstained amniotic fluid (MSAF) represents a risk factor for postpartum hemorrhage (PPH) after vaginal delivery in a large unselected population.

Patients and methods: A retrospective cohort study evaluated 78,542 consecutive women who had a vaginal delivery between 24th and 44th weeks of gestation. The women who had undergone cesarean section were excluded to avoid possible bias. Postpartum blood loss was measured with graduated blood sack. Postpartum blood loss between 1,000 and 2,000 mL and $>2,000 \mathrm{~mL}$ were classified as moderate and severe $\mathrm{PPH}$, respectively.

Results: A total of 74,144 patients were available for analysis. According to the color of amniotic fluid (AF), two groups of patients were identified: MSAF $(n=10,997)$ and clear AF $(n=63,147)$. The rates of severe and massive PPH were found to be significantly higher in the MSAF group than that of clear AF group (OR=1.3, 95\% CI: $1.2-1.5, p<0.001$ and $\mathrm{OR}=2.5$, $95 \%$ CI: $1.5-4.2, p<0.001)$. Operative vaginal delivery rate was found to be higher in the MSAF group than that of clear AF group, but the difference was only borderline significant $(\mathrm{OR}=1.5$, 95\% CI: $1.0-2.2, p=0.05$ ). There were no significant differences between the MSAF and the clear AF groups with respect to episiotomies, second- or third-degree perineal tears, vaginalperineal thrombus, cervical lacerations, vaginal births after cesarean section, twin deliveries, and placental retention rates.

Conclusion: To the best of our knowledge, this is the first clinical study that has investigated the role of MSAF as a risk factor for PPH after vaginal delivery in an unselected population. Our results suggest that MSAF is significantly associated with higher risk of moderate and severe PPH than clear AF.

Keywords: amniotic fluid, delivery complications, meconium, postpartum hemorrhage

\section{Introduction}

Postpartum hemorrhage (PPH) is one of the leading causes of maternal mortality. ${ }^{1}$ Several recent population-based studies have observed an increasing trend in the incidence of PPH over time. ${ }^{2,3}$ Several factors, such as maternal age, obesity, grand multiparity, uterine fibroids, previous cesarean delivery, multiple pregnancy, placenta previa or abruption, preeclampsia/eclampsia, amnionitis, fetal macrosomia, labor induction, instrumental vaginal delivery, cesarean delivery, cervical laceration, and uterine rupture have been associated with high risk of major PPH..$^{3-8}$ Moreover, recently, new risk factors have been identified, including index of multiple deprivation (education, skills, and training), multiparity without cesarean section, and antenatal administration of steroids. ${ }^{9}$ 
Amniotic fluid (AF) contains many coagulation factors which exert procoagulant, anticoagulant, and fibrinolytic activities. ${ }^{10-19}$ A thrombogenic role of amniotic cells has also been well documented. ${ }^{20}$ In an animal model, it has been shown that the infusion of AF causes activation of coagulation. ${ }^{21}$ This effect was significantly more pronounced by injecting $\mathrm{AF}$ contaminated with meconium. ${ }^{21}$

Unfortunately, there are scant clinical data on the impact of meconium on the risk of maternal hemorrhage. The only published study found no significant differences in the rate of hemorrhage between the patients with meconium-stained amniotic fluid (MSAF) and clear AF. ${ }^{22}$ However, only patients with preterm delivery were included. Moreover, a very low rate of $\mathrm{PPH}(<0.6 \%)$ was observed. ${ }^{22}$

In this study, we aimed to determine whether MSAF represents a risk factor for PPH after vaginal delivery in a large unselected population.

\section{Patients and methods}

The study population consisted of 78,542 consecutive women who had a vaginal delivery at IRCCS Burlo Garofolo, Trieste, Italy, from May 1972 to December 2013, between 24th and 44th weeks of gestation. Data were collected from the delivery room records.

The women who had undergone cesarean section were excluded to avoid possible bias. As a matter of fact, blood loss during the cesarean section can be estimated only with wide approximation. ${ }^{23}$ In addition, these cases have a high risk of hemorrhage due to surgery ${ }^{3}$ and the incidence of stained AF could have been much higher, given the significant number of fetal distress as indication for cesarean section. ${ }^{24}$ Finally, the site of entry of AF is through beant venous vessels in placental site and through venous vessels in delivery channel that get lacerated by fetal passage; therefore, we excluded the potential passage through hysterotomic wound that happens in cesarean section. We collected data regarding the color of $\mathrm{AF}$ and postdelivery blood loss. According to the color of AF, two groups of patients were identified: MSAF and clear AF. MSAF includes any meconium: fresh, old, thick (dark green in color and of pea soup consistency with particulate matter), or thin (lightly stained yellow or greenish color). ${ }^{25,26}$

In all patients, postpartum blood loss was measured with graduated blood sack. Postpartum blood losses were measured using graduated blood drape consistently over the entire 41 years. The drape was placed under the buttocks of the woman immediately after delivery and drainage of the AF. Blood loss was assessed for at least 1 hour after delivery of the baby. Whenever persistent bleeding occurred, blood loss was measured until active bleeding stopped. ${ }^{27,28}$
PPH was defined as a cumulative postpartum blood loss $\geq 1,000 \mathrm{~mL}$ according to the American College of Obstetricians and Gynecologists (ACOG) nomenclature consensus conference (reVITALize). ${ }^{29}$ Postpartum blood loss between 1,000 and 2,000 $\mathrm{mL}$ and $>2,000 \mathrm{~mL}$ were classified as moderate and severe PPH, respectively.

Chi-square test and Fisher's exact test, when appropriate, were used to examine the relationship between the presence of MSAF and categorical parameters. OR and 95\% CIs were calculated. A $p$-value $<0.05$ was considered statistically significant. Statistical analysis was performed using GraphPad Prism version 6 (GraphPad Software, Inc., La Jolla, CA, USA).

The study was approved by the Ethical Committee of IRCCS Burlo Garofolo, Trieste, on April 14th 2015 with protocol Number $759 / 2015$. It was not necessary to obtain informed consent in this study as the regulatory standards in Italy do not require consent for a retrospective study; patients' data were treated with extreme confidentiality for strictly scientific purposes.

\section{Results}

A total of 78,452 deliveries were evaluated. In about $2.5 \%$ of the cases, blood loss was considered, but the color of AF was not described. In $0.1 \%$ of the cases, $\mathrm{AF}$ was absent or not reported. In about $3 \%$ of the cases, blood loss was not reported. Finally, data of a total of 74,144 patients were available for analysis.

There were 10,997 cases (14.8\%) with MSAF and 63,147 cases $(85.2 \%)$ with clear AF. The rates of moderate PPH (blood loss between 1,000 and 2,000 mL) and severe PPH (blood loss $>2,000 \mathrm{~mL}$ ) were found to be significantly higher in the MSAF group than that of clear AF group (Table 1). MSAF was found to be significantly associated with high risk of moderate $\mathrm{PPH}(\mathrm{OR}=1.3,95 \% \mathrm{CI}: 1.2-1.5)$ and severe $\mathrm{PPH}$ (OR=2.5, 95\% CI: 1.4-4.2) (Table 1). The operative vaginal deliveries with vacuum or forceps were higher in the MSAF group than that of clear AF group, but the difference was only borderline significant ( $\mathrm{OR}=1.5,95 \% \mathrm{CI}: 1.0-2.2, p=0.05)$. There were no statistically significant differences between

Table I Postpartum blood loss in meconium-stained amniotic fluid (MSAF) and clear amniotic fluid (AF) group

\begin{tabular}{|c|c|c|c|c|}
\hline $\begin{array}{l}\text { Blood loss } \\
(\mathrm{mL})\end{array}$ & $\begin{array}{l}\text { MSAF, n (\%) } \\
(n=10,997)\end{array}$ & $\begin{array}{l}\text { Clear AF, n (\%) } \\
(n=63,147)\end{array}$ & $\begin{array}{l}\text { OR } \\
(95 \% \mathrm{Cl})\end{array}$ & $p$-value \\
\hline$<1,000$ & $10,670(97)$ & 61,762 (97.8) & 1 & \\
\hline $1,000-2,000$ & $307(2.8)$ & I,338 (2.1) & $1.3(1.2-1.5)$ & $<0.001$ \\
\hline$>2,000$ & $20(0.2)$ & $47(0.1)$ & $2.5(1.5-4.2)$ & $<0.001$ \\
\hline
\end{tabular}


the clear AF group and the MSAF group regarding episiotomies, second- or third-degree perineal tears, vaginal-perineal thrombus, cervical lacerations, vaginal births after cesarean section, twin deliveries, and placental retention requiring manual placental removal.

\section{Discussion}

In this study, we examined a very large population of women who had vaginal delivery. We collected data regarding the color of AF and postdelivery blood loss. The incidence of deliveries with MSAF was found to be $14.8 \%$, which is slightly higher than what is reported by the other authors. ${ }^{30-32}$ However, it may be influenced by the fact that between 1972 and 2004, delivery management was to wait, in most cases, for spontaneous labor till the 42nd week. Several studies have reported that MSAF proportionally increases with the increase of gestational age. ${ }^{24,33,34} \mathrm{We}$ observed a significant increase in the risk of moderate and severe PPH in the presence of MSAF. Our results do not agree with those of the other clinical studies published so far. Mazor et $\mathrm{al}^{22}$ found that MSAF was not a risk factor for PPH. However, it should be noticed that this study included only preterm delivery and that a very low rate of PPH was reported. ${ }^{22}$

We are unable to explain why meconium may increase the risk of hemorrhage. The coagulation and fibrinolysis in AF have been extensively investigated. Most proteins of the coagulation and fibrinolysis system, and many vasoactive and procoagulant substances, such as platelet activating factor, cytokines, bradykinin, thromboxane, leukotrienes, and arachidonic acid have been detected in AF. ${ }^{10-19}$

However, data regarding the effects of MSAF on coagulation and fibrinolysis system are scarce; there is no such data with respect to human beings, and there are only few animal studies on this topic. Petroianu et $\mathrm{al}^{21}$ showed that the infusion of native AF (including meconium) triggered a response similar to disseminated intravascular coagulation (DIC). After infusion of centrifuged AF (excluding meconium), in spite of the much higher volumes used, the changes were less pronounced. The authors concluded that the factor (or factors) initiating DIC after infusion of native AF are unknown and are probably contained in meconium, since meconium-free AF is not life-threatening even if very high volumes are infused. ${ }^{21}$ Similar results have been obtained in pregnant goats where left ventricular dysfunction and dysoxia were observed only with the infusion of AF containing meconium. ${ }^{35}$

Recently, it has been observed that the injection of autologous AF induced a transient and severe thrombocytopenia, but not AF embolism in a rabbit model. ${ }^{35}$ However, thromboelastographic analysis indicated that AF could initiate the cascade of coagulation. The authors concluded that other factors such as the presence of meconium in AF may be needed to provoke more severe clinical signs. ${ }^{36}$ Since AF cannot be absorbed through vaginal mucosa, it can be hypothesized that coagulopathy and subsequent hemorrhage are caused by the entrance of AF into maternal circulation. It has been reported that this event is frequent, ${ }^{37}$ and several cases of AF embolism with isolated coagulopathy have been reported ${ }^{38-44}$ If AF is contaminated by meconium, the severity of coagulopathy and hemorrhage might significantly increase. In fact, we have observed that in patients with MSAF, the rates, both of moderate and severe hemorrhages were significantly higher than that of clear AF group.

In this study, we found a higher, although not significant, incidence of MSAF in operative deliveries than that of other studies. $^{45-47}$ This may be due to higher incidence of fetal hypoxia in these cases involving a higher risk of meconium release during the labor. ${ }^{47}$ Several other hypotheses have been suggested to explain this finding. Meconium has been associated with fetal heart rate abnormalities ${ }^{48}$ that may induce physicians to an aggressive obstetric management. The presence of meconium per se may cause physician concern for fetal well-being thus lowering the threshold for intervention. ${ }^{46}$ Meconium might negatively influence the regular labor progression, perhaps through subclinical infection. ${ }^{46}$ Experimental studies showed that meconium may inhibit the umbilical vessel smooth muscle contractile effect of a thromboxane A2 analog. ${ }^{49}$ Finally, it is possible that meconium inhibits uterine smooth muscle contraction and increases the risk of labor dystocia and operative delivery. ${ }^{46}$

This study has some advantages. To the best of our knowledge, this is the first clinical, specifically addressed study that has investigated the role of MASF as risk factor for $\mathrm{PPH}$ in an unselected population of pregnant women. It is a single center study and it included data from a very large number of deliveries, thus reducing the role of potential confounding factors. The study also has some limitations. It is, in fact, a retrospective study over a long span of time and assessment of AF characteristics was eye-based, which may include bias due to subjective evaluation. Moreover, data were collected from the delivery room records and some information regarding antenatal complications of pregnancy were lacking.

\section{Conclusion}

Our results suggest that MSAF is significantly associated with higher risk of moderate and severe PPH than clear AF. Therefore, in case of MASF, more attention should be paid 
to postpartum bleeding. Further studies are needed to clarify the mechanism by which meconium increases the risk of hemorrhage.

\section{Disclosure}

The authors report no conflicts of interest in this work.

\section{References}

1. Sheldon WR, Blum J, Vogel JP, Souza JP, Gülmezoglu AM, Winikoff B; WHO Multicountry Survey on Maternal and Newborn Health Research Network. Postpartum haemorrhage management, risks, and maternal outcomes: findings from the World Health Organization Multicountry Survey on Maternal and Newborn Health. BJOG. 2014; 121(Suppl 1):5-13.

2. Knight M, Callaghan WM, Berg C, et al. Trends in postpartum hemorrhage in high resource countries: a review and recommendations from the International Postpartum Hemorrhage Collaborative Group. BMC Pregnancy Childbirth. 2009;9:55.

3. Kramer MS, Berg C, Abenhaim $\mathrm{H}$, et al. Incidence, risk factors, and temporal trends in severe post-partum hemorrhage. Am J Obstet Gynecol. 2013;209(5):449.e1-449.e7.

4. Ngwenya S. Postpartum hemorrhage: incidence, risk factors, and outcomes in a low-resource setting. Int $J$ Womens Health. 2016;8:647-650.

5. Khireddine I, Le Ray C, Dupont C, Rudigoz RC, Bouvier-Colle MH, Deneux-Tharaux C. Induction of labor and risk of postpartum hemorrhage in low risk parturients. PLoS One. 2013;8(1):e54858.

6. Gollop ND, Childs CA, Coupe B, MacFarlane S, Burrell J, Kumar B. Body weight, body image and primary postpartum haemorrhage: a review of the literature. J Obstet Gynaecol. 2014;34(5):373-382.

7. Sentilhes L, Merlot B, Madar H, Sztark F, Brun S, Deneux-Tharaux C. Postpartum haemorrhage: prevention and treatment. Expert Rev Hematol 2016;9(11):1043-1061.

8. Miller CM, Cohn S, Akdagli S, Carvalho B, Blumenfeld YJ, Butwick AJ. Postpartum hemorrhage following vaginal delivery: risk factors and maternal outcomes. J Perinatol. 2017;37(3):243-248.

9. Briley A, Seed PT, Tydeman G, et al. Reporting errors, incidence and risk factors for postpartum haemorrhage and progression to severe PPH: a prospective observational study. BJOG. 2014;121(7):876-888.

10. Weiner AE, Reid DE. The pathogenesis of amniotic fluid embolism. III. Coagulant activity of amniotic fluid. N Engl J Med. 1950;243(16): 597-598.

11. Philips LL, Davidson EC Jr. Procoagulant properties of amniotic fluid. Am J Obstet Gynecol. 1972;113(7):911-919.

12. Omsjø IH, Øian P, Maltau JM, Østerud B. Thromboplastin activity in amniotic fluid. Gynecol Obstet Invest. 1985;19(1):1-5.

13. Estellés A, Gilabert J, Andrés C, España F, Aznar J. Plasminogen activator inhibitors type 1 and type 2 and plasminogen activators in amniotic fluid during pregnancy. Thromb Haemost. 1990;64(2):281-285.

14. Lockwood CJ, Bach R, Guha A, Zhou X, Miller WA, Nemerson Y. Amniotic fluid contains tissue factor, a potent initiator of coagulation. Am J Obstet Gynecol. 1991;165(5 Pt 1):1335-1341.

15. Sarig G, Klil-Drori AJ, Chap-Marshak D, Brenner B, Drugan A. Activation of coagulation in amniotic fluid during normal human pregnancy. Thromb Res. 2011;128(5):490-495.

16. Uszyński M, Uszyński W. Coagulation and fibrinolysis in amniotic fluid: physiology and observation on amniotic fluid embolism, preterm fetal membrane rupture, and pre-eclampsia. Semin Thromb Hemost. 2011;37(2):165-174.

17. Uszyński W, Zekanowska E, Uszyński M, Zyliński A, Kuczyński J. New observations on procoagulant properties of amniotic fluid: microparticles (MPs) and tissue factor-bearing MPs (MPs-TF), comparison with maternal blood plasma. Thromb Res. 2013;132(6):757-760.
18. Liu S, Wei L, Zhang Y, Xu M, Wang C, Zhou J. Procoagulant activity and cellular origin of microparticles in human amniotic fluid. Thromb Res. 2014;133(4):645-651.

19. Uszyński W, Żekanowska E, Uszyński M, Kieszkowski P. Activation contact system (ACS) and tissue factor (TF) in human amniotic fluid: measurements of ACS components and TF, and some implications on the pathophysiology of amniotic fluid embolism. Thromb Res. 2015;135(4):699-702.

20. Zhou J, Liu S, Ma M, et al. Procoagulant activity and phosphatidylserine of amniotic fluid cells. Thromb Haemost. 2009;101(5):845-851.

21. Petroianu GA, Altmannsberger SH, Maleck WH, et al. Meconium and amniotic fluid embolism; effects on coagulation in pregnant mini-pigs. Crit Care Med. 1999;27(2):348-355.

22. Mazor M, Hershkovitz R, Bashiri A, et al. Meconium stained amniotic fluid in preterm delivery is an independent risk factor for perinatal complications. Eur J Obstet Gynecol Reprod Biol. 1998;81(1):9-13.

23. Gluck O, Mizrachi Y, Kovo M, Divon M, Bar J, Weiner E. Major underestimation and overestimation of visual blood loss during cesarean deliveries: can they be predicted? Arch Gynecol Obstet. 2017; 296(5):907-913.

24. Hiersch L, Krispin E, Aviram A, Wiznitzer A, Yogev Y, Ashwal E. Effect of meconium-stained amniotic fluid on perinatal complications in low-risk pregnancies at term. Am J Perinatol. 2016;33(4):378-384.

25. Cialone PR, Sherer DM, Ryan RM, Sinkin RA, Abramowicz JS. Amnioinfusion during labor complicated by particulate meconium-stained amniotic fluid decreases neonatal morbidity. Am J Obstet Gynecol. 1994;170(3):842-849.

26. Bhat RY, Rao A. Meconium-stained amniotic fluid and meconium aspiration syndrome: a prospective study. Ann Trop Paediatr. 2008; 28(3):199-203.

27. Patel A, Goudar SS, Geller SE, et al. Drape estimation vs. visual assessment for estimating postpartum hemorrhage. Int J Gynaecol Obstet. 2006;93(3):220-224.

28. Ambardekar S, Shochet T, Bracken H, Coyaji K, Winikoff B. Calibrated delivery drape versus indirect gravimetric technique for the measurement of blood loss after delivery: a randomized trial. BMC Pregnancy Childbirth. 2014;14:276.

29. American College of Obstetricians and Gynecologists. reVITALize obstetric data definitions. Available from: http://www.acog.org/-/media/ Departments/Patient-Safety-and-Quality-Improvement/2014reVITAL izeObstetricDataDefinitionsV10.pdf. Accessed July 25, 2018.

30. Khazardoost S, Hantoushzadeh S, Khooshideh M, Borna S. Risk factors for meconium aspiration in meconium stained amniotic fluid. $J$ Obstet Gynaecol. 2007;27(6):577-579.

31. Walsh MC, Fanaroff JM. Meconium stained fluid: approach to the mother and the baby. Clin Perinatol. 2007;34(4):653-665.

32. Bhat R, Vidyasagar D. Delivery room management of meconiumstained infant. Clin Perinatol. 2012;39(4):817-831.

33. Fischer C, Rybakowski C, Ferdynus C, Sagot P, Gouyon JB. A population-based study of meconium aspiration syndrome in neonates born between 37 and 43 weeks of gestation. Int J Pediatr. 2012; 2012:321545.

34. Hiersch L, Krispin E, Linder N, et al. Meconium-stained amniotic fluid and neonatal morbidity in low-risk pregnancies at term: the effect of gestational age. Am J Perinatol. 2017;34(2):183-190.

35. Hankins GD, Snyder RR, Clark SL, Schwartz L, Patterson WR, Butzin CA. Acute haemodynamic and respiratory effects of amniotic fluid embolism in the pregnant goat model. Am J Obstet Gynecol. 1993; 168(4):1113-1130.

36. Rannou B, Rivard GE, Gains MJ, Bédard C. Intravenous injection of autologous amniotic fluid induces transient thrombocytopenia in a gravid rabbit model of amniotic fluid embolism. Vet Clin Pathol. 2011;40(4):524-529.

37. Shamshirsaz AA, Clark SL. Amniotic fluid embolism. Obstet Gynecol Clin North Am. 2016;43(4):779-790. 
38. Porter TF, Clark SL, Dildy GA, Hankins GDV. Isolated disseminated intravascular coagulation and amniotic fluid embolism. Am J Obstet Gynecol. 1996;174:486.

39. Davies S. Amniotic fluid embolism and isolated disseminated intravascular coagulation. Can J Anaesth. 1999;46(5 Pt 1):456-459.

40. Awad IT, Shorten GD. Amniotic fluid embolism and isolated coagulopathy: atypical presentation of amniotic fluid embolism. Eur $J$ Anaesthesiol. 2001;18(6):410-413.

41. Levy R, Furman B, Hagay ZJ. Fetal bradycardia and disseminated coagulopathy: atypical presentation of amniotic fluid embolism. Acta Anaesthesiol Scand. 2004;48(9):1214-1215.

42. Yang JI, Kim HS, Chang KH, Ryu HS, Joo HJ. Amniotic fluid embolism with isolated coagulopathy: a case report. J Reprod Med. 2006;51(1):64-66.

43. Matsuzawa Y, Furukawa S, Kiyomoto C, Fujiwara M, Mochizuki M. Different clinical courses with severe postpartum coagulopathy in two cases showing the same histological findings those local amniotic fluid emboli. J Syndromes. 2016;3:4.

44. Liao CY, Luo FJ. Amniotic fluid embolism with isolated coagulopathy: a report of two cases. J Clin Diagn Res. 2016;10(10):QD03-QD05.
45. Maymon E, Chaim W, Furman B, Ghezzi F, Shoham Vardi I, Mazor M Meconium stained amniotic fluid in very low risk pregnancies at term gestation. Eur J Obstet Gynecol Reprod Biol. 1998;80(2):169-173.

46. Tran SH, Caughey AB, Musci TJ. Meconium-stained amniotic fluid is associated with puerperal infections. Am J Obstet Gynecol. 2003; 189(3):746-750.

47. Becker S, Solomayer E, Dogan C, Wallwiener D, Fehm T. Meconiumstained amniotic fluid - perinatal outcome and obstetrical management in a low-risk suburban population. Eur J Obstet Gynecol Reprod Biol. 2007;132(1):46-50.

48. Nathan L, Leveno KJ, Carmody TJ 3rd, Kelly MA, Sherman ML. Meconium: a 1990s perspective on an old obstetric hazard. Obstet Gynecol. 1994;83(3):329-332.

49. Montgomery LD, Belfort MA, Saade GR, Moise KJ Jr, Vedernikov YP. Meconium inhibits the contraction of umbilical vessels induced by the thromboxane A2 analog U46619. Am J Obstet Gynecol. 1995; 173(4):1075-1078.
Therapeutics and Clinical Risk Management

\section{Publish your work in this journal}

Therapeutics and Clinical Risk Management is an international, peerreviewed journal of clinical therapeutics and risk management, focusing on concise rapid reporting of clinical studies in all therapeutic areas outcomes, safety, and programs for the effective, safe, and sustained use of medicines. This journal is indexed on PubMed Central, CAS,

\section{Dovepress}

EMBase, Scopus and the Elsevier Bibliographic databases. The manuscript management system is completely online and includes a very quick and fair peer-review system, which is all easy to use. Visit http://www.dovepress.com/testimonials.php to read real quotes from published authors.

Submit your manuscript here: http://www.dovepress.com/therapeutics-and-clinical-risk-management-journal 